\title{
GESTURE-VERBAL UTTERANCES FROM THE COGNITIVE PERSPECTIVE
}

\author{
Alla Martynyuk \\ V.N. Karazin Kharkiv National University, Kharkiv, Ukraine \\ allamartynyuk@ukr.net
}

\begin{abstract}
The article develops the idea of speech and gesture as an integral system of generation of meaning viewing an individual's cognitive system as a dynamic, evolving semantic lattice organising semantic items of propositional and imagistic modes around a core meaning: linguistic items (propositions) are linked to ideas, concepts and beliefs as well as to specific feelings, mental states, images of gestures and stereotypic patterns of behaviour. Since gesture and speech are equally engaged in generation of meaning, they are treated in terms of gesture-verbal utterances as minimal material carriers of semantic content, activating the semantic lattice. According to the sphere of human consciousness / sub-consciousness which is basically 'responsible' for their production and interpretation, gesture-verbal utterances are divided into rational classifying / qualifying (activating semantic structure to provide information, helping classify or qualify the referents of the utterances), emotional (activating emotional attitudes) and suggestive (activating no semantic content but organising narration over large spans). Rational gesture-verbal utterances are further classified on the basis of the semiotic principle, governing the gestural activation of semantic structure, into deictic (pointing to the referent), iconic (depicting the referent) and symbolic (standing for the referent) and also into literal and metaphoric in accordance with the image-realistic or image-schematic principle of depicting the referent.
\end{abstract}

Keywords: generation of meaning; gesture; speech; imagistic mode; propositional mode; semantic lattice.

\section{Introduction}

Though scientific research on communicative value of nonverbal behaviour started as early as 1872 with the publication of Ch. Darwin's book "The Expression of the Emotions in Man and Animals", intensive studies of nonverbal communication began only in the second half of the past century (Efron, 1941; Goffman, 1955; Birdwhistell, 1970; Kendon, 1972, 1980; Scheflen, 1964, 1973).

Since then nonverbal behaviour has been looked upon as a special semiotic code, separate from the code of spoken language. However, paradoxical as it may seem, at the same time, nonverbal behaviour has still been interpreted in the same terms of 'coding/decoding' as linguistic signs. Thus, "The Concise Corsini Encyclopedia of Psychology and Behavioral Science" (2004) states:

"Nonverbal communication involves the conscious and unconscious processes of encoding and decoding. Encoding is the act of generating information such as facial expressions, gestures, and postures. Decoding is the interpretation of information from received sensations from previous experiences." (p. 627)

An alternative approach to nonverbal communication, aiming to account for this discrepancy, was launched by McNeill's research on gesture (1992) which brought him to the conclusion that it is "profoundly an error to think of gesture as a code or 'body language', separate from spoken language" $(2005$, p. 4) since gesture and speech make up an integrated system of meaning expression. In McNeill's papers, this fruitful hypothesis is addressed from the perspective of formal semantics which simplifies descriptions of the interface between language and thought due to reductionist and mechanistic outlook of the formal paradigm.

The primary objective of this paper is to develop the idea of speech and gesture as an integral system of generation of meaning with the heuristic apparatus provided by Hardy's advanced cognitive theory of semantic constellations (1998) which bridges the gap between cognitive semantics, with its schemas and semantic networks, and modern process-oriented cognitive science.

It is argued here that gesture and speech form an integral system of generation of meaning, functioning as gesture-verbal utterances, i.e. material carriers of semantic content that activate semantic lattice, organising semantic structure of propositional and imagistic modes around the activated semantic content.

\section{Nonverbal communication within the framework of formal semantics}

The view of nonverbal behaviour as a special semiotic code has been fed by the formal (structural) approach to language, put forward by de Saussure (1977), where language is seen as a formal hierarchal symbolic system. According to F. de Saussure, there is no natural connection between the shape of a word and the image it brings about (p. 100). There is no reason why the letters T-R-E-E (or the sound of the word TREE) produce exactly the image of a tall plant that has a thick, wooden stem and many large leafy branches.

In scientific terms this connection is called arbitrary (based on chance rather than reason). It is believed to be a result of 'convention' which basically means that speakers of the same language group have agreed 
(and learned) that certain letters or sounds evoke a certain image. Though, on second thought, this concept of linguistic convention appears rather shaky (it is next to impossible to explain how people could agree about meaning at the time when they had no tool to come to any agreement as language was just in the process of development and no connections between forms and meanings have yet been established), the assumption of conventional nature of the linguistic sign is still accepted by the majority of linguists as one of linguistic axioms.

To explain the difference between language (langue) and speech (parole) de Saussure (1977) draws an analogy to chess. He compares language as a system to the set of chess figures each having its meaning for the players and a set of rules for playing the game. Speech is compared to the moves that an individual chooses to make, the individual's preferences in playing the game (de Saussure, 1977, p. 61).

This line of reasoning prompts the assumption that linguistic meaning is compositional: not only word meaning is composed of semantic primitives, but sentence meaning is also composed of word meaning, together with the structure imposed on those words by the grammar of sentences. Thus sentence meanings can be predicted from context-independent meanings of individual words and their grammatical properties and any contextual variability of meanings can be accounted for by pragmatic rules and principles.

Within the formal approach semantics and pragmatics are viewed as separate disciplines with different subject matters: while the former deals with meanings encoded in words, regardless of their context of use, the latter is concerned with intentions of the speakers and the hearers' making use of contextual information to retrieve the speakers' meanings by constructing inferences. While both semantic and pragmatic meanings interact to give rise to the interpretation of an utterance, the formal model holds that only semantic meaning, being 'purely linguistic', belongs in the lexicon.

Thus, according to the formal view, linguistic meaning is compositional, separate from 'world knowledge', and can be modeled according to precise and formally stated definitions.

This idea underpins the so-called code model of communication - the assumption that people understand each other through encoding and decoding messages contained in linguistic signs as if they were containers with meanings. To be able to communicate people have to know these correlations between forms and meanings of language signs and the rules of combining them to express all kinds of ideas. Within this framework, body movements are treated as containers with meanings to be encoded and decoded similar to linguistic signs.

The problem with this view is that body language lacks language properties: whereas (from the formal perspective) spoken language is conventionalised and compositional, body language is mostly nonconventionalised and certainly non-compositional, it is idiosyncratic and imagistic.

In his first book on speech and gesture, McNeill (1992) postulates that because gesture and speech temporally overlap but convey information in two very different semiotic modes these two modes capture and reflect different aspects of a unitary cognitive process. I should make it clear that McNeill is primarily concerned with spontaneous speech-linked gestures (gesticulations) which are obligatorily accompanied by speech but lack language-like properties being non-conventionalised and non-compositional (in his terms 'synthetic/global'), and leaves language-like pantomime and signs of sing language and also standing-inbetween emblems (the terms are from Kendon's 'continuum' (1988)) beyond the scope of his attention.

Other researchers of nonverbal behaviour have also claimed that gesture and speech create a tightly integrated system of language production and comprehension (Clark, 1996; Goldin-Meadow, 2003; Kelly, Manning, \& Rodak, 2008; Kendon, 2004; Kita \& Özyürek, 2003; Özyürek \& Kelly, 2007).

In "Introduction" to his second book, adding new tenets to his theory, McNeill (2005) points out that while in the first book the emphasis was on how gestures reveal thought; now it is how gestures fuel thought and speech: when imagery and linguistic content are combined, they create the so-called 'growth point' a minimal unit of dialectic which "[c]ontains opposite semiotic modes of meaning capture - instantaneous, global, nonhierarchical imagery with temporally sequential, segmented, and hierarchical language. $<\ldots>$ The key to the dialectic is that the two modes are simultaneously active in the mental experience of the speaker. Simultaneously representing the same idea unit in opposite modes creates instability, a 'benevolent instability' that is resolved by accessing forms on the static dimension - constructions and lexical choices, states of repose par excellence." (p. 18)

The problem with the 'growth point' is, as I see it, that it is based on the formal semantics understanding of the interface between language and thought which can hardly be reconciled with the commitments of cognitive science whose main concern is to reveal the nature of this interface. 


\section{Nonverbal communication within the framework of cognitive science}

Cognitive semanticists (Fillmore, 1885; Fauconnier, 1997; Lakoff, 1987; Langacker, 1987, 2001, 2013; Turner, 1991) view meaning encoded in language, i.e. semantic structure, as a partial and incomplete representation of conceptual structure. Semantic structure is specialised for expression via spoken or written symbols and restricted to information derived from the visual and auditory channels. Conceptual structure is multimodal: it is underpinned by information derived from our sensory experience involving all the five sensory channels. Besides, conceptual structure also relies on our introspective experience involving reflection on our inner bodily, emotional and mental states.

From the cognitive perspective linguistic knowledge cannot be separated in a principled way from 'world' knowledge, nor can 'semantic' knowledge be separated from 'pragmatic' knowledge; the kinds of knowledge subsumed under these headings constitute a continuum. The so-called coded meanings (conventional meanings associated with words) are abstracted from the range of contexts of use associated with any given word. Furthermore, words are sometimes used in ways that are only partially sanctioned by these coded meanings: language use is often innovative. The degree to which any given usage of a coded meaning is innovative varies according to contextual factors.

Another important cognitive assumption is the embodied cognition thesis: the idea that conceptual structure arises from bodily experience. In other words, conceptual structure is meaningful in part because of the bodily experiences with which it is associated: cognitive semanticists conceive meaning as the imaginative projection of bodily experience onto abstract cognitive models.

This basically means that from the cognitive perspective language is ontologically inseparable from sensory imagery which motivates linguistic meaning.

Furthermore, within the cognitive model of semantics, meanings are seen as construed in the act of speech rather than encoded/decoded 'ready-made'. A body of conceptual content associated with a linguistic unit used by the speaker is regarded as a prompt which provides raw material for the process called conceptualisation, i.e. an array of cognitive operations recruiting conceptual structure (encyclopaedic knowledge) for construing linguistic meaning within a context. Thus, conceptual structures are seen as partly stable (stored) knowledge systems and partly dynamic (on-line) conceptualisations creating a semantic network of interrelated concepts.

This approach is not new. It was first suggested within linguistics by Moore \& Carling (1982) and has been supported by a number of cognitive linguists (see, for instance, Croft \& Cruse, 2004; Koskela, 2014; Kugler, 2014; Lakoff \& Sweetser, 1994; Paradis, 2011; Tylén, Fusaroli, Bundgaard \& Østergaard, 2013; Verspoor, Schmid \& Xu, 2012).

Within the framework of cognitive semantics which adopts a constructional rather than compositional view of meaning where it is described as an integral part of 'world knowledge', i.e. conceptual structure arising from sensory imagery, the opposition between 'instantaneous, global, nonhierarchical imagery' gesture and 'sequential, segmented, and hierarchical' language, underpinning McNeill's 'growth point', loses its relevance.

At the same time, McNeill's idea of gesture and speech making up an integrated system of meaning expression acquires a new perspective.

As it was shown by Martynyuk (2016), besides the impact of encyclopaedic knowledge, generation of meaning in an act of communication is also influenced by other psychological factors. These psychological factors are enhanced by the term 'context' which refers to:

1) cognitive context, i.e. encyclopaedic knowledge (ontological, ethological (norms of social behaviour) and lingua-ethological (norms of communicative behaviour); universal, lingua-cultural, lingua-social and individual;

2) emotional context (emotional attitudes to the referents / communicants);

3) perceptive context (immediate perceptive experience coming from all the five sensory channels, being activated by the perceptual input, i.e. verbal utterances and nonverbal behaviour of the communicants, and becoming part of cognitive/emotional context viewed as 'semantic lattice' of related concepts, feelings, attitudes, moods, patterns of behaviour, desires, internal images of words, gestures, etc.; 'stored' in long-term memory and acquired here and now; concerning both: the referents (entities spoken about) and the communicants (speakers).

The notion of 'semantic lattice' belongs to Hardy (1998) who represents an individual's cognitive structure as dynamical, evolving matrix of semantic constellations, i.e. an ensemble of linked semantic elements (concepts, internal images, sensations, gestures, moods, behaviours, and so on) organised around a core meaning. The semantic lattice governs the conscious and largely unconscious process of generating 
meaning based upon a wide variety of connections such as contiguity, metaphor, analogy, contradiction, differentiation, and more.

Since gesture and speech are equally engaged in generation of meaning, it seems more relevant to speak about gesture-verbal utterances rather than speech utterances and speech-linked gesticulations as separate items.

A gesture-verbal utterance is addressed as a material carrier of semantic content activating bigger ensembles of semantic elements where linguistic items (propositions) are linked not only to ideas, concepts and beliefs but also to specific feelings, mental states, images, stereotypic patterns of behaviour, organised around the activated semantic content.

The product of meaning generation process is treated here in terms of inference, which is viewed as socio-culturally and contextually motivated individual semantic structure emerging in the act of communication as a result of complex conscious and unconscious cognitive processes recruiting elements of the semantic lattice.

The range of inferences includes:

1) rational classifying/qualifying inferences taking shape of identification/categorisation or assessment of the referents of the gesture-verbal utterances and also of the communicants;

2) emotional inferences resulting from emotional attitudes evoked by the referents and communicants;

3) subconscious inferences fed by implicit knowledge and intuition which underpin generation of meaning since conscious thought is just the end product of the internal connective processes at work in the semantic lattice.

This classification of inferences provides the grounds for classification of gesture-verbal utterances according to the sphere of human consciousness / sub-consciousness which is basically 'responsible' for their production and interpretation into rational classifying / qualifying, emotional and suggestive.

On the other hand, on the basis of their function in the narration, gesture-verbal utterances are divided into narrative (referring to the events of the narration) and metanarrative (arranging the narration).

Rational classifying gesture-verbal utterances tend to be narrative, activating semantic structure to provide information helping identify/classify the referents of the utterances.

The semiotic principle of gestural activation of semantic structure in the consciousness of the communicants splits rational classifying gesture-verbal utterances into: deictic (where gestures index, or connect, some object in the communicative space to some aspect of speech by pointing to this object); iconic (where gestures imagistically depict referents of gesture-verbal utterances (objects, actions and spatial relationships)); and symbolic (emblems) (where gestures stand for referents as conventionalised signs).

Deictic and iconic rational classifying gesture-verbal utterances, being universal, natural, mostly subconscious and speech-linked ways of meaning expression, differ from emblems (like the 'OK' gesture made with the second finger and thumb) which, being conventionalised and mostly culturally specific, are not necessarily speech-linked.

The difference between the image-realistic and image-schematic principle of depicting the referent underpins the division of rational classifying gesture-verbal utterances into literal deictic and iconic where gestures point to / imagistically depict some concrete physical object and metaphoric deictic and iconic where gestures point to / imagistically depict some abstract object.

To give an example of a literal deictic narrative gesture-verbal utterance, let me refer you to "The Tonight Show Starring Jimmy Fallon", specifically the episode with the American pop-singer Miley Syrus, where Jimmy Fallon and his guest discuss the uncanny resemblance between the photos of her knee cap and the photos of some American celebrities' faces. In the middle of this discussion Jimmy Fallon says: So, this is interesting, this is your kneecap here, and simultaneously points to the photo of Miley's kneecap.

A metaphoric deictic narrative gesture-verbal utterance involves pointing to some abstract 'object', like for instance, pointing to FUTURE with the extended arm and hand moving forward. This kind of gesture accompanies Jimmy Fallon's question addressed to Gisele Bündchen, a super-model who finishes her modelling career: What's your PLANs, what're you gonna do? (Capital letters mark emphatic stress). This gesture-verbal utterance represents the bi-modal conceptual metaphor FUTURE is AHEAD: the target domain is implicitly expressed by the verbal utterance, specifically by the lexical unit PLANs, associated with the future, and the source domain is expressed by the gesture (the hand pointing ahead). This metaphor is common to many cultures, and has been researched extensively as an orientational conceptual metaphor by Lakoff \& Johnson (2003, p. 15-25).

An example of a literal iconic narrative gesture-verbal utterance comes from the above-mentioned episode of "The Tonight Show Starring Jimmy Fallon" with Miley Syrus where Jimmy Fallon accompanies 
his utterance Your KNEE, your kneecap, is an imPERsonator with a hand gesture actually showing the form of a knee cap.

A metaphoric iconic narrative gesture-verbal utterance can be illustrated by a bi-modal implementation of the classical conceptual ontological metaphor IDEAS are OBJECTS (Lakoff \& Johnson, 2003, p. 47-48): during a brainstorming session on a new advertising campaign, a marketing executive says: Here's what I am thinking, while holding her fingers at her forehead and temples, and then suddenly thrusting them outward as if holding an object out to the group (Kelly, Manning \& Rodak, 2008, p. 2). The target domain of this metaphor is implicitly represented by the verbal utterance, actually introducing an idea, and the source domain is expressed by the gesture. It is impossible to physically remove an idea from one's head and literally present it to others, so the gesture, in this case, conveys that meaning in an image-schematic manner, as if IDEA were a material object.

Rational qualifying gesture-verbal utterances, which are also narrative, evoke semantic structure dealing with the assessment of the referents of the utterances. In the above-mentioned episode with Miley Syrus at some point in discussion Miley expresses her assessment of the resemblance between the photos of her knee cap and the photos of some American celebrities' faces by the utterance This is freaky. The utterance is accompanied by such a gesture: her arms are bent, both hands with palms down move forward and down away from her body and are kept in this down position for some time as if she were protecting herself from something under her palms. According to the principle of imagistic gestural representation, this utterance is metaphoric. It represents the bi-modal orientational conceptual metaphor FREAKY is DOWN: the target concept is explicitly expressed by the word freaky, and the source concept is expressed by the gesture. This metaphor gives a negative assessment to its target concept since in American culture DOWN is associated with negative assessment, so this metaphor happens to be maximally coherent with GOOD is UP / BAD is DOWN (Lakoff \& Johnson, 2003, p. 18).

Emotional narrative gesture-verbal utterances express emotional attitudes of the communicants toward the referent of the utterance. For example, at some point of the interview with Miley Syrus Fallon repeatedly bangs his open hand with palm down on the table while laughing at the resemblance between the photos of her knee cap and the photos of some American celebrities' faces.

Suggestive metanarrative gesture-verbal utterances are associated with beat gestures, i.e. hand movements that keep the rhythm of speech. These gestures are not thought to convey any semantic content, but they do connect portions of narrative over large spans. Also, they rythmisise speech and in this way automatise its comprehension. For example, if a speaker enumerates some objects and his right hand repeatedly flips outward every time he mentions another object throughout the sequence, it creates a sense of rhythm and cohesive structure.

\section{Conclusions}

The idea of speech and gesture as an integral system of meaning generation makes up a coherent whole within the advanced cognitive framework where an individual's cognitive system is addressed as a dynamic, evolving semantic lattice where linguistic items (propositions) are linked to ideas, concepts and beliefs as well as to specific feelings, mental states, images and stereotypic patterns of behaviour, organised around a core meaning, and where conscious thought is the end product of the internal connective processes at work.

The product of meaning generation process is best treated in terms of inference, i.e. socio-culturally and contextually motivated individual semantic structure emerging in the act of communication as a result of complex conscious and unconscious internal connective processes in the semantic lattice.

Classification of inferences into conscious (rational, emotional) and subconscious provides the grounds for classification of gesture-verbal utterances according to the sphere of human consciousness / subconsciousness which is basically 'responsible' for their production and interpretation.

Rational classifying and qualifying gesture-verbal utterances activate semantic structure to provide information helping classify or qualify the referents of the utterances (and also communicants). Emotional gesture-verbal utterances activate emotional attitudes. Suggestive gesture-verbal utterances activate no semantic content but organise the narration over large spans.

Rational gesture-verbal utterances are further classified on the basis of the semiotic principle, governing the gestural activation of semantic structure, into deictic (pointing to the referent), iconic (depicting the referent) and symbolic (standing for the referent) and also into literal and metaphoric in accordance with the image-realistic or image-schematic principle of representing the referent.

Addressing gesture-verbal utterances as material carriers activating semantic lattice, i.e. a network of interlinked semantic elements of imagistic and propositional modes, organised around the activated content, opens a new perspective in understanding generation of meaning in communication. 
References:

Birdwhistell, R.L. (1970). Kinesics and context. Philadelphia: University of Pennsylvania Press. https://doi.org/10.9783/9780812201284

Clark, H.H. (1996). Using language. Cambridge, UK: Cambridge University Press. http://dx.doi:10.1017/CBO9780511620539.

Efron, D. (1941). Gesture and Environment. New York: King's Crown Press.

Fauconnier, G. (1997). Mappings in thought and language. Cambridge, U.K.: Cambridge University Press. https://doi.org/10.1017/cbo9781139174220

Fillmore, Ch. (1985). Frames and the semantics of understanding. Quaderni di Semantica, 6(2), 222-253.

Goffman, E. (1955). On face-work: An analysis of ritual elements in social interaction. Psychiatry: Interpersonal and Biological Processes, 18, 213-231. https://doi.org/10.1080/00332747.1955.11023008

Goldin-Meadow, S. (2003). Hearing gesture: how our hands help us think. Cambridge, MA: Belknap Press of Harvard University.

Hardy, C. (1998). Networks of meaning: A bridge between mind and matter. Wesport, Connecticut; London: Praeger, 1998.

Kelly, S. D., Manning, S.M., \& Rodak, S. (2008). Gesture Gives a Hand to Language and Learning: Perspectives from Cognitive Neuroscience, Developmental Psychology and Education. Language and Linguistics Compass, 2(4), $569-588$. http://dx.doi:10.1111/j.1749-818X.2008.00067

Kendon, A. (1972). Some relationships between body motion and speech. An analysis of an example. In A. Siegman \& B. Pope (Eds.), Studies in Dyadic Communication, (pp. 177-210). Elmsford, New York: Pergamon Press. https://doi.org/10.1016/b978-0-08-015867-9.50013-7

Kendon, A. (1980). Gesticulation and speech: two aspects of the process of utterance. In M.R. Key (ed.). The Relationship of Verbal and Nonverbal Communication, (pp. 207-227). The Hague: Mouton and Co. https://doi.org/10.1515/9783110813098.207

Kendon, A. (1988). How gestures can become like words. In F. Poyatos (ed.). Cross-Cultural Perspectives in Nonverbal Communication, (pp. 131-141). Toronto: Hogrefe.

Kendon, A. (2004). Gesture: visible action as utterance. Cambridge, UK: Cambridge University Press. https://doi.org/10.1017/cbo9780511807572

Kita, S., \& Özyürek, A. (2003). What does cross-linguistic variation in semantic coordination of speech and gesture reveal? Evidence for an interface representation of spatial thinking and speaking. Journal of Memory and Language, 48, 16-32. http://dx.Doi:10.1016/S0749-596X(02)00505-3

Koskela, A. (2014). Shoes, boots and vertical polysemes: The dynamic construal and conventionality of word senses. Review of Cognitive Linguistics, 12 (2), 259-287. http://dx.doi.org/10.1075/rcl.12.2.01kos

Kugler N. (2014). The dynamic construal of epistential meaning. Argumentum, 10, 403-420.

Lakoff, G. (1987). Women, fire and other dangerous things. What categories reveal about mind. Chicago and London: Chicago University Press.

Lakoff, G., \& Johnson, M. (2003). Metaphors we live by. Chicago, IL: University of Chicago Press. https://doi.org/10.7208/chicago/9780226470993.001.0001

Lakoff, G., \& Sweetser, E. (1994). Foreword to Gilles Fauconnier, Mental Spaces, (pp. ix-xlvi). Cambridge: Cambridge University Press. https://doi.org/10.1017/cbo9780511624582.001

Langacker, R. (2001). Discourse in cognitive grammar. Cognitive Linguistics 12, 2, 143-188. https://doi.org/10.1515/cogl.12.2.143

Langacker, R. (2013). Essentials of cognitive grammar. New York: Oxford University Press.

Langacker, R. W. (1987). Foundations of cognitive grammar. Vol. 1. Theoretical prerequisites. Stanford: Stanford University Press. http://dx.doi:10.1515/cogl.1993.4.1.1

McNeill, D. (1992). Hand and mind. Chicago: Chicago University Press.

McNeill, D. (2005). Gesture and thought. Chicago: Chicago University Press. http://dx.doi:10.7208/chicago/9780226514642.001.0001

Moore, T., \& Carling, Ch. (1982). Understanding language: towards a post-Chomskyan linguistics. London: Macmillan. http://dx.doi.org/10.1007/978-1-349-16895-8

Özyürek, A., \& Kelly, S.D. (2007). Gesture, brain, and language. Brain and Language, 101(3), 181-184. http://dx.doi.org/10.1016/j.bandl.2007.03.006

Paradis C. (2011). A dynamic construal approach to antonymy. Selected Papers from the 19th ISTAL (pp. 33-42). Retrieved from www.enl.auth.gr/symposium19/19thpapers/003 Paradis.pdf

Scheflen, A.E. (1964). The significance of posture in communication systems. Psychiatry: Journal of Interpersonal Relations, 27, 316-331. http://dx.doi.org/10.1080/00332747.1964.11023403

Scheflen, A.E. (1973). Communication structure: Analysis of a psychotherapy transaction. Bloomington: Indiana University Press.

Turner, M. (1991). Reading minds: the study of English in the age of cognitive science. Princeton, New York: Princeton University Press.

Tylén, K., Fusaroli R., Bundgaard P. \& Østergaard S. (2013). Making sense together: A dynamical account of linguistic meaningmaking. Semiotica, 194, 39-62. https://doi.org/10.1515/sem-2013-0021

Verspoor, M., Schmid, M. S., \& Xu, X. (2012). A dynamic usage based perspective on L2 writing. Journal of Second Language Writing, 21 (3), 239-263. https://doi.org/10.1016/j.jslw.2012.03.007

The Concise Corsini Encyclopedia of Psychology and Behavioral Science (2004). Hoboken, NJ: Wiley.

Martynyuk, A. (2016). Kognitivno-kommunikativnaja lingvistika: v poiskah bazovyh principov i metodik analiza [Cognitivecommunicative linguistics: in search of basic principles and tools of analysis]. Kognicija, kommunikacija, diskurs, 12, 1735. Retrieved from https://sites.google.com/site/cognitiondiscourse/vypusk-no12-2016/martynuk-a-p .

Sossjur, F. de. (1977). Trudy po jazykoznaniju. [Papers in linguistics]. (A.A. Holodovich, Transl.). Moscow, Russia: Progress Publ. References of illustrative material:

The Tonight Show Starring Jimmy Fallon. Retrieved from https://www.youtube.com/user/latenight . 